\title{
The Luminescent Properties and Atomic Structures of As-Grown and Annealed Nanostructured Silicon Rich Oxide Thin Films
}

\author{
N. D. Espinosa-Torres, J. A. D. Hernández-de-la-Luz, J. Martínez-Juárez, \\ J. F. J. Flores-Gracia, and J. A. Luna-López \\ CIDS-ICUAP Benemérita Universidad Autónoma de Puebla, C.U., Edif. 103 C-D, Col. San Manuel, 72570 Puebla, PUE, Mexico
}

Correspondence should be addressed to N. D. Espinosa-Torres; siox130@gmail.com

Received 5 June 2016; Revised 10 September 2016; Accepted 3 October 2016

Academic Editor: Wenrui Zhang

Copyright (C) 2016 N. D. Espinosa-Torres et al. This is an open access article distributed under the Creative Commons Attribution License, which permits unrestricted use, distribution, and reproduction in any medium, provided the original work is properly cited.

\begin{abstract}
Not long ago, we developed a theoretical model to describe a set of chemical reactions that can potentially occur during the process of obtaining Silicon Rich Oxide (SRO) films, an off stoichiometry material, notwithstanding the technique used to grow such films. In order to elucidate the physical chemistry properties of such material, we suggested the chemical reactions that occur during the process of growing of SRO films in particular for the case of the Low Pressure Chemical Vapor Deposition (LPCVD) technique in the aforementioned model. The present paper represents a step further with respect to the previous (published) work, since it is dedicated to the calculation by Density Functional Theory (DFT) of the optical and electronic properties of the as-grown and annealed SRO structures theoretically predicted on the basis of the previous work. In this work, we suggest and evaluate either some types of molecules or resulting nanostructures and we predict theoretically, by applying the DFT, the contribution that they may have to the phenomenon of luminescence (PL), which is experimentally measured in SRO films. We evaluated the optical and electronic properties of both the as-grown and the annealed structures.
\end{abstract}

\section{Introduction}

SRO thin films have been studied lengthily and are very fascinating due to their optoelectronic properties, particularly those related with luminescence. In general, the luminescent properties can provide significant information regarding the crystalline structure of a material and, in the case of SRO thin films, their luminescence properties are considered of great importance since these films can be used to fabricate luminescent devices [1].

When SRO thin films are annealed, the oxides are degraded. For example, for $\mathrm{SiO}_{2}$ and $\mathrm{Si}_{2} \mathrm{O}_{3}$ the believable annealing reactions were proposed by Espinosa-Torres [2], although the possibility that other oxides could be formed during the deposition process exists.

A well-known fact, as reported in scientific works, is that SRO films can be obtained, among other techniques, by using the LPCVD technique employing silane and nitrous oxide as precursory gases. The key effect of thermal treatment consists in the development of structural transformations due to elimination of oxygen and hydrogen atoms, which leads as final result to the formation of small agglomerates of silicon atoms and defects due to the vacancies of oxygen atoms. It is worth noting that the as-grown SRO films could contain substoichiometric oxides and nanoparticles of silicon (Si-nps). Fourier Transform Infrared (FTIR) measurements evidenced that thermal annealing results in a phase separation and then Si-nps embedded in stoichiometric oxide matrix are produced [3]. However, to date there is no clear explanation on the increase of photoluminescence after the heat treatment in films SiOx obtained experimentally. The PL has been linked to the formation of silicon nanocrystals or to defects formed in the matrix and interface SiOx-Si-ncs. As a consequence, this is a clear motivation for this simulation in order to try to discern which of these phenomena contributes to the PL emission. Therefore these theoretical calculations are intended to model the behavior of the structures proposed to approximate their FTIR spectra, PL, and UV-Vis to the 
TABLE 1: Comparison of experimental results versus theoretical calculations. Energy of the optical bang gap obtained experimentally by Tauc's method for SRO films with different Ro values and times of thermal treatment.

\begin{tabular}{|c|c|c|c|c|c|}
\hline \multirow[b]{3}{*}{ Ro } & \multicolumn{4}{|c|}{ Band gap, $(\mathrm{eV})$} & \\
\hline & \multicolumn{3}{|c|}{$\begin{array}{l}\text { Annealed at } 1100^{\circ} \mathrm{C} \\
\text { (experimental results) }\end{array}$} & \multicolumn{2}{|c|}{ Theoretical results } \\
\hline & $30 \mathrm{~min}$ & $60 \mathrm{~min}$ & $180 \mathrm{~min}$ & Structure & Calculated band gap, $(\mathrm{eV})$ \\
\hline 10 & $2.4 \pm 0.04$ & $2.4 \pm 0.02$ & $2.43 \pm 0.04$ & $\begin{array}{c}\mathrm{Si}_{11} \mathrm{O}_{11}: \mathrm{H}_{12} \text { (completely hydrogen } \\
\text { saturated structure or as-grown } \\
\text { structure) }\end{array}$ & 5.766 \\
\hline \multirow[t]{3}{*}{20} & $3.57 \pm 0.03$ & $3.6 \pm 0.06$ & $3.69 \pm 0.03$ & $\mathrm{Si}_{11} \mathrm{O}_{11}$ (fully annealed structure) & 2.709 \\
\hline & & & & $\mathrm{Si}_{14} \mathrm{O}_{14}: \mathrm{H}_{12}$ & 5.221 \\
\hline & & & & $\mathrm{Si}_{14} \mathrm{O}_{14}: \mathrm{H}_{10}$ & 4.656 \\
\hline \multirow{4}{*}{30} & $3.73 \pm 0.06$ & $3.86 \pm 0.04$ & $3.89 \pm 0.04$ & $\mathrm{Si}_{14} \mathrm{O}_{14}: \mathrm{H}_{8}$ & 4.611 \\
\hline & & & & $\mathrm{Si}_{14} \mathrm{O}_{14}: \mathrm{H}_{6}$ & 4.495 \\
\hline & & & & $\mathrm{Si}_{14} \mathrm{O}_{14}: \mathrm{H}_{4}$ & 4.404 \\
\hline & & & & $\mathrm{Si}_{14} \mathrm{O}_{14}$ (fully annealed structure) & 3.256 \\
\hline
\end{tabular}

spectra obtained experimentally in order to understand, which are the physical processes that allow us to explain the observed PL.

In this research, we employed the Density Functional Theory with a functional B3LYP and a basis set $6-31 \mathrm{G}^{*}$ to calculate the optical and electronic properties of $\mathrm{Si}_{n} \mathrm{O}_{n}$ and $\mathrm{Si}_{n} \mathrm{O}_{n}: \mathrm{H}_{x}$ nanostructures with the aim of contributing to a better understanding of the luminescent phenomena observed in the SRO thin films. In a previous published work [4], we have already modeled different silicon nanoclusters, so in the present paper we only focus on the $\mathrm{Si}_{n} \mathrm{O}_{n}$ oxide structures.

\section{Results and Discussion}

2.1. Band Gap Calculations. There are different factors that have an important influence on the optical properties of the SRO films. Factors such as the support substrate type, silicon excess, annealing temperatures, time of thermal treatment, and composition at deposition moment and subsequent transformations are very important factors which play an important role to determine the optical properties of the SRO films. Particularly, PL of samples deposited by LPCVD also depends on the partial pressure ratio between $\mathrm{N}_{2} \mathrm{O}$ and $\mathrm{SiH}_{4}$ defined as $\mathrm{Ro}=\left[\mathrm{N}_{2} \mathrm{O} / \mathrm{SiH}_{4}\right]$ and thermal annealing conditions [5].

In Table 1 we present our results for theoretically calculated values of band gaps for the structures $\mathrm{Si}_{11} \mathrm{O}_{11} \mathrm{H}_{12}$, $\mathrm{Si}_{11} \mathrm{O}_{11}, \mathrm{Si}_{14} \mathrm{O}_{14}$, and $\mathrm{Si}_{14} \mathrm{O}_{14} \mathrm{H}_{m}(m=12,10,8,6$, and 4$)$. We consider that $\mathrm{Si}_{11} \mathrm{O}_{11}$ and $\mathrm{Si}_{14} \mathrm{O}_{14}$ refer to the fully annealed oxides, whereas $\mathrm{Si}_{11} \mathrm{O}_{11} \mathrm{H}_{12}$ and $\mathrm{Si}_{14} \mathrm{O}_{14} \mathrm{H}_{12}$ refer to the asgrown oxides. In Table 1 , the experimental values of band gaps obtained in [5] for the SRO with different Ro and different times of annealing at $1200^{\circ} \mathrm{C}$ are presented. The experimental values were obtained by Tauc method proposed for amorphous materials. In general, for the annealing time of $180 \mathrm{~min}$, the SRO films could be considered as fully annealed (dehydrogenated). As one can see, the calculated values for $\mathrm{Si}_{11} \mathrm{O}_{11}$ and $\mathrm{Si}_{14} \mathrm{O}_{14}$ lie in the interval of experimental values for the annealed SRO. Moreover, the calculated value of band gap for $\mathrm{Si}_{14} \mathrm{O}_{14}$ is greater than that for $\mathrm{Si}_{11} \mathrm{O}_{11}$. It is probable that in the annealed SRO with Ro $\geq 20$ [5] (see Table 1) the number of $\mathrm{Si}$ or $\mathrm{O}$ atoms in the $\mathrm{Si}_{n} \mathrm{O}_{n}$ structure is greater than 16.

2.2. FTIR and PL Calculations. The FTIR and PL spectra given in Figure 1 are the first results obtained of our numerical simulations for atomic structures of the type $\mathrm{Si}_{n} \mathrm{O}_{n}: \mathrm{H}_{m}$. In the right side of Figure 1, we display the calculated molecular structure, considered as-grown, for $\mathrm{Si}_{11} \mathrm{O}_{11}: \mathrm{H}_{12}$ (a) and in (b) the new structure, that is, when it has been fully annealed: $\mathrm{Si}_{11} \mathrm{O}_{11}$. The most remarkable difference is observed in the correspondent FTIR (top of both figures). The as-grown structure displays vibrational frequencies due to $\mathrm{Si}-\mathrm{H}$ bonds in a frequency of $2281.404 \mathrm{~cm}^{-1}$ and the structure after annealing process does not exhibit any vibration around this frequency. Also, in Figure 1 we can observe that the structure as-grown $\left(\mathrm{Si}_{11} \mathrm{O}_{11}: \mathrm{H}_{12}\right)$ emits energy in the violet region (Figure 1(a)), while the corresponding annealed structure, displayed on Figure 1(b), which corresponds with PL spectrum for $\mathrm{Si}_{11} \mathrm{O}_{11}$ ), is also able to emit light in visible region.

Also, in Figure 1 are displayed the corresponding structures for $\mathrm{Si}_{11} \mathrm{O}_{11}: \mathrm{H}_{12}$ and $\mathrm{Si}_{11} \mathrm{O}_{11}$. For the structure $\mathrm{Si}_{11} \mathrm{O}_{11}: \mathrm{H}_{12}$ we have incorporated the electrostatic potential map (an electrophilic indicator) for an isovalue of $-83.68 \mathrm{KJ} / \mathrm{mol}$, and we have labeled the silicon, oxygen, and hydrogen atoms. This gives the electrostatic potential at locations on a particular surface, most commonly a surface of electron density corresponding to overall molecular size [6], whereas, for the $\mathrm{Si}_{11} \mathrm{O}_{11}$ structure, we have included the Local Ionization Potential Map (LIPM) for an isovalue of 20 (without units or dimensionless). LPIM reflects the relative straightforwardness of electron removal (“ionization”) at any location around a molecule. The numbers near the different atoms in the structure $\mathrm{Si}_{11} \mathrm{O}_{11}$ are the calculated Mulliken charges.

FTIR vibrations modes and their corresponding frequency of vibrations in the as-deposited and after annealed 


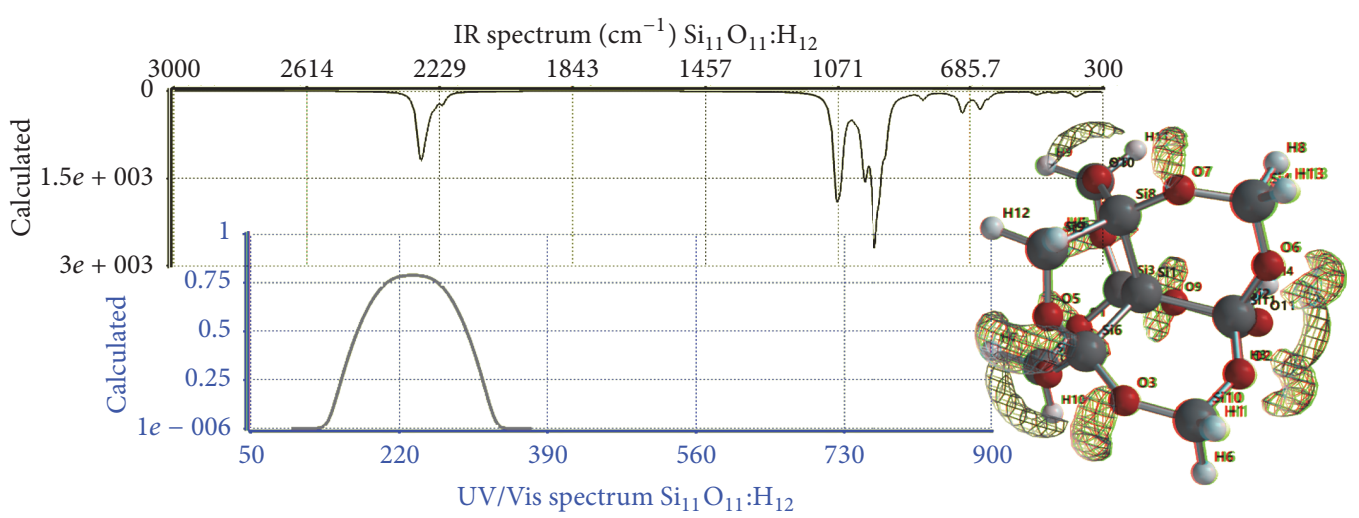

(a)

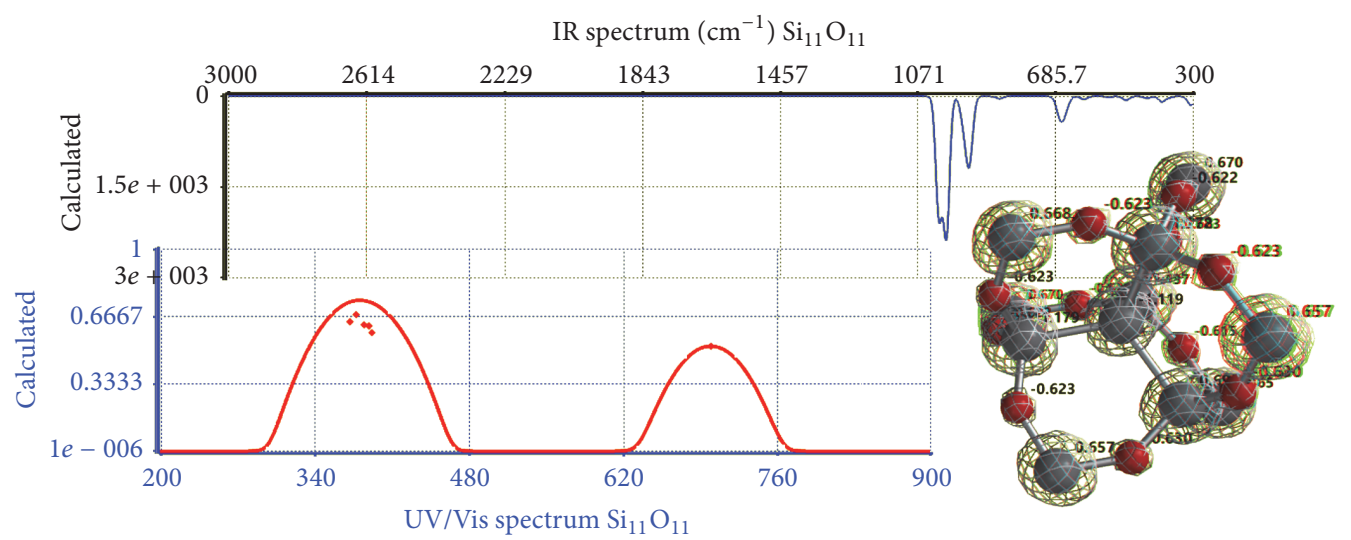

(b)

FIgURE 1: (a) Molecular structure with eleven silicon atoms $\mathrm{Si}_{11} \mathrm{O}_{11}: \mathrm{H}_{12}$ (as-grown), UV/Vis spectrum with only one luminescence peak in $\mathrm{UV}$ region and IR spectrum with a peak due to $\mathrm{Si}-\mathrm{H}$ bond; (b) fully annealed $\mathrm{Si}_{11} \mathrm{O}_{11}$ molecular nanostructure, UV-Vis spectrum displaying luminescence in two regions (UV and visible) and IR spectrum without peak owing to Si-H bond.

SRO films, considering silica and SRO films with different values of Ro, are consigned in literature [2]. The values commonly found are Si-O rocking $458-450 \mathrm{~cm}^{-1}$, Si-O bending $815-805 \mathrm{~cm}^{-1}$, Si-O stretching on phase $1061-1082 \mathrm{~cm}^{-1}$, and Si-O stretching out of phase $1160-1185 \mathrm{~cm}^{-1}$.

The three most intense peaks in the calculated FTIR spectra of as-grown structure correspond with frequencies of $962.355,995.002$, and $1067.44 \mathrm{~cm}^{-1}$. It was found that the total number of calculated vibrations for as-grown structure was 96 different modes. The last one value of frequency calculated $\left(1067.44 \mathrm{~cm}^{-1}\right)$ fits well with experimental data previously reported for $\mathrm{Si}-\mathrm{O}$ stretching on phase, whereas for the annealed structure the three most intense peaks calculated were 930.909, 990.752, and $1012.774 \mathrm{~cm}^{-1}$ and there are only 60 frequencies of vibration (there are no longer $\mathrm{Si}-\mathrm{H}$ bonds). These results obtained suggest that SRO films experimentally annealed were not completely passivated.

The calculated proposal includes structures type $\mathrm{Si}_{11} \mathrm{O}_{11}$, which contain twelve $\mathrm{Si}-\mathrm{Si}$ bonds. The annealed structure $\mathrm{Si}_{11} \mathrm{O}_{11}$ gives us a frequency of vibration at $669.029 \mathrm{~cm}^{-1}$ and we confirm that it is due to Si-Si bonds. Again, these results have a good correlation with experimental results earlier reported for Ro $=30[7,8]$. With respect to as-grown and thermally treated PL calculated spectra, we predict luminescence in ultraviolet region in $251.34 \mathrm{~nm}$ in only one band for the film originally deposited. When the nanostructure is fully passivated, this band moves or shifts to $377.58 \mathrm{~nm}$ (yet in ultraviolet) and a second band of emission centered at $699.24 \mathrm{~nm}$ appears, giving a red emission.

Emission in red region has been evidenced experimentally for SRO films with Ro $=10,20$, and 30, but the movement of the band into ultraviolet region has not been noticed or it has not yet been reported, probably due to the interest focused on only in emission in visible region.

Figure 2 displays the calculated FTIR spectra for different silicon oxide clusters size for structures fully annealed (dehydrogenated) $\mathrm{Si}_{n} \mathrm{O}_{n}$ for $n=5,11,14,16,17$, and 19. We have constructed the Gaussian type curves with FWHH $=20 \mathrm{~nm}$ and selected the scale from 300 to $1500 \mathrm{~cm}^{-1}$ (there are not any data calculated beyond this interval). For the intensities we choose a scale of 0-4000 in arbitrary units for all the cases presented in Figure 2. Only in the spectrum which corresponds with $n=16$ we predicted the Si-O rocking type vibrations in interval from 417 to $429 \mathrm{~cm}^{-1}$ and it has a quite small intensity. A probable explanation for this fact is that $\mathrm{Si}-\mathrm{O}$ rocking type vibration observed experimentally could 


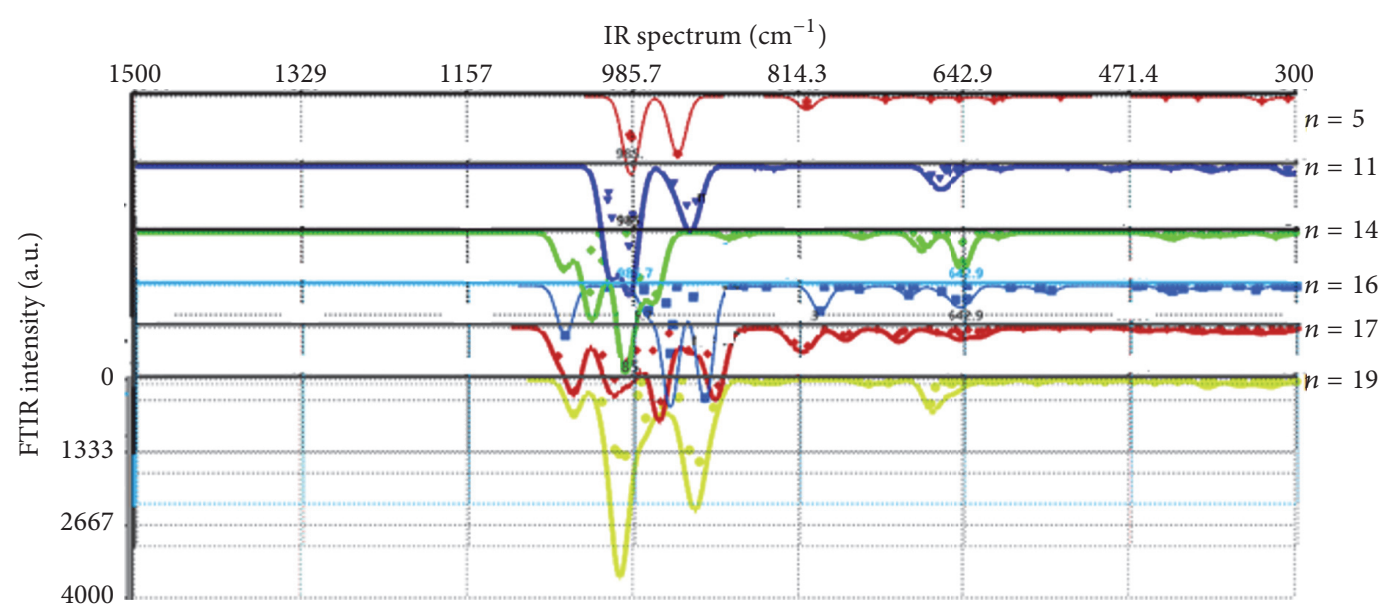

FIGURE 2: FTIR spectra calculated for $\mathrm{Si}_{n} \mathrm{O}_{n}$ (fully annealed structures), varying the number of silicon atoms for $n=5,11,14,16,17$, and 19 .

be due to other kinds of oxides existing in SRO thin films, like $\mathrm{SiO}_{2}$ and $\mathrm{Si}_{2} \mathrm{O}_{3}$ [9].

The intensity of the frequencies of vibration for bonds $\mathrm{Si}-\mathrm{O}$ is increased accordingly as the number of silicon atoms is increased in the agglomerates studied. The vibrations calculated, during the numerical simulations, for bending type $\mathrm{Si}-\mathrm{O}$ bond were predicted in the interval from 751 to $840 \mathrm{~cm}^{-1}$ as follows: $n=5$ (806), $n=11$ (840), $n=14$ (751), $n=16$ (794), $n=17$ (821), and $n=19$ (833). Some of these vibrations have a quite small intensity and they are not visible to the naked eye.

For the second stage of this study, we choose a bigger structure $\left(\mathrm{Si}_{14} \mathrm{O}_{14}\right)$ but maintaining the $\mathrm{Si} / \mathrm{O}$ ratio. Figure 2 corresponds with as-grown case. The analysis and discussion are similar to the structure shown in the first stage of this study, and as relevant results we found that there are only small variations in the values calculated; for example, the frequency vibration due to $\mathrm{Si}-\mathrm{H}$ bond appears in the frequency interval from 2262.084 to $2307.217 \mathrm{~cm}^{-1}$, being the most intense at $2265.384 \mathrm{~cm}^{-1}$. Of course, in the cited interval there are twelve calculated vibrations due to $\mathrm{Si}-\mathrm{H}$ bond. Only in the structure which corresponds with fully annealed condition the vibration due to $\mathrm{Si}-\mathrm{H}$ vanishes completely.

In Figures 3-8 we present results of an evolution in the structure assuming the constant loss of pairs of hydrogen atoms. The points drawn outside of the curves in FTIR and PL spectra in Figures 3-8 correspond with the vibrational frequencies calculated and the points displayed in PL spectra are the wavelength of calculated emission states. Then the curves correspond with the predicted observable spectra. The points calculated for the frequencies of vibration in FTIR spectra and the wavelengths of emission in PL spectra, being in close proximity, add constructively. As a result of the foregoing, an increase in the intensity of the spectra will be observed. Therefore the solid line in the resulting spectra observed will not always cross the calculated points. The width of the peaks in the spectra of vibration and width of the luminescent bands will depend on the thickness of the SRO films.
Numerical data are consigned in Table 2. We predict again the shift of the ultraviolet band. For structures type $\mathrm{Si}_{14} \mathrm{O}_{14}$ we confirm that there is only one band which resembles two bands overlapped. The results predict emission in a wide range from violet to orange color. Experimentally, the luminescence in this range has been reported due to cathode luminescence in SRO films (see Figure 8 of [10]) for asgrown and annealed films, mainly for Ro $=20$ and 30, when an energy excitation of $5 \mathrm{keV}$ and $0.3 \mathrm{~mA}$ current was used [9]. Additionally, the interested audience in experimental emission of as-grown SRO films with Ro $=30$ is motivated to review [11].

Data in Table 2, for wavelength with the highest intensity of emission $(\mathrm{nm})$ in UV-Vis spectrum, fits exactly with the next quadratic equation:

$$
\lambda=4.9542 n^{2}-51.442 n+444.4
$$

With $R^{2}=1$, in this equation $\lambda$ is the highest intensity of emission (nm) and $n$ is the number of hydrogen atoms in the structure.

Unfortunately, it is not easy to give an acceptable explanation of this finding in this moment, because there are necessary additional studies of the kinetic of set of reactions, and experimentally it is not possible to isolate only one reaction during the deposition process.

Regarding Figure 8, $\mathrm{Si}_{14} \mathrm{O}_{14}$ displays a wide emission range, which looks like two bands overlapped. Theoretically it is possible to model the thickness of SRO samples varying the FWHH and in this way we can obtain a separated twoband spectrum. In our simulations, we apply the FWHH value which corresponds to experimental samples typically found in the literature in which usually PL spectrum with a single band is reported. Then, our calculations predict the possibility of new mechanisms for emission in SRO thin films with an "extreme dwarf thickness."

The experimental FTIR absorption spectra of as-grown and thermally treated SRO films with different silicon excess that are shown in Figure 9 were adapted from Espinosa-Torres [2]. The original interval for experimental data displayed 


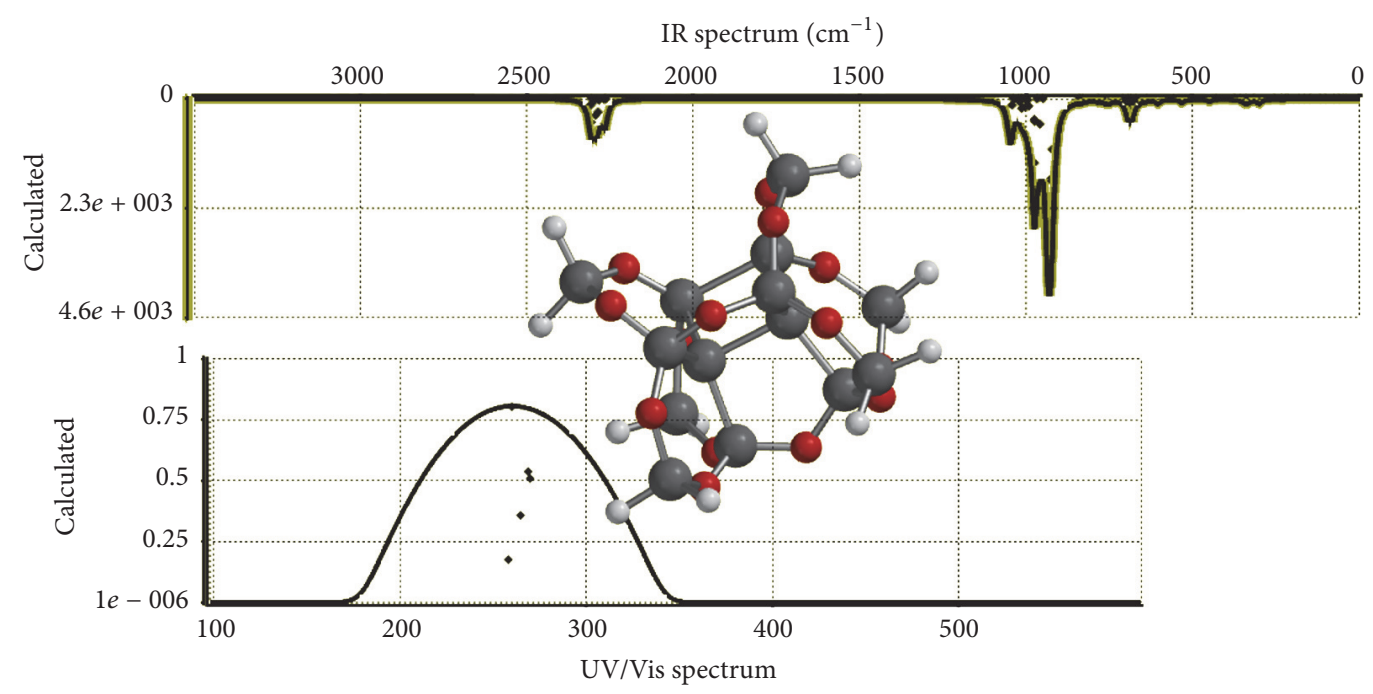

Figure 3: Case $\mathrm{Si}_{14} \mathrm{O}_{14}: \mathrm{H}_{12}$.

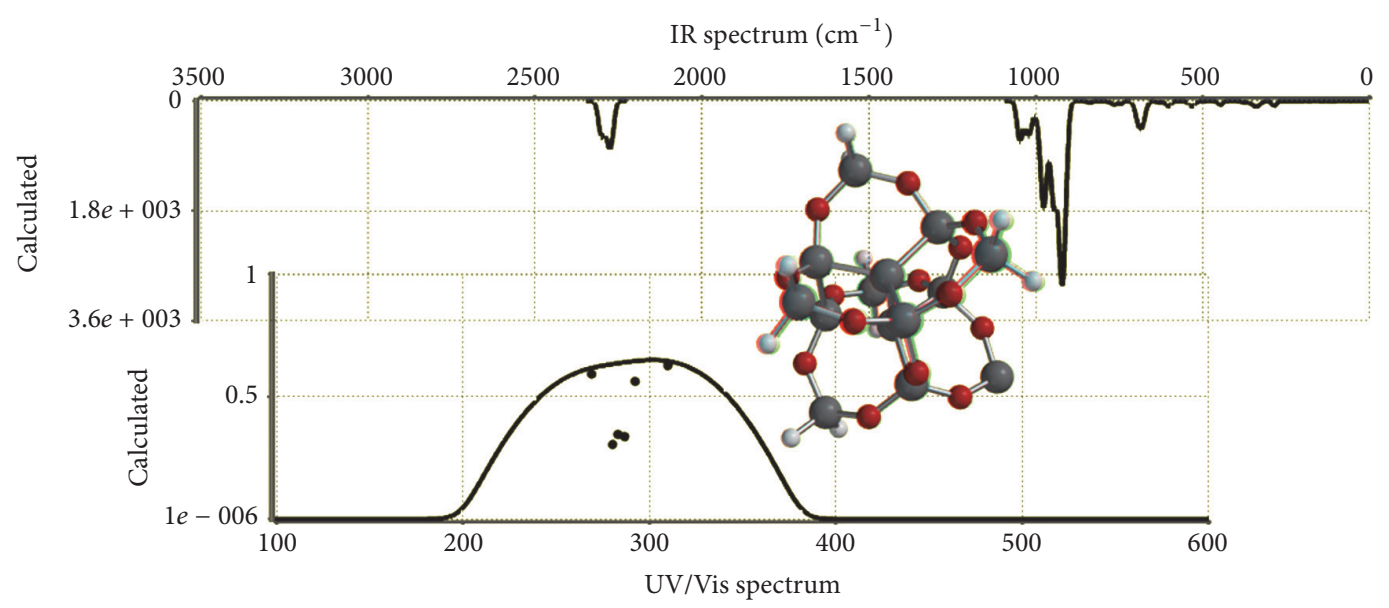

Figure 4: Case $\mathrm{Si}_{14} \mathrm{O}_{14}: \mathrm{H}_{10}$.

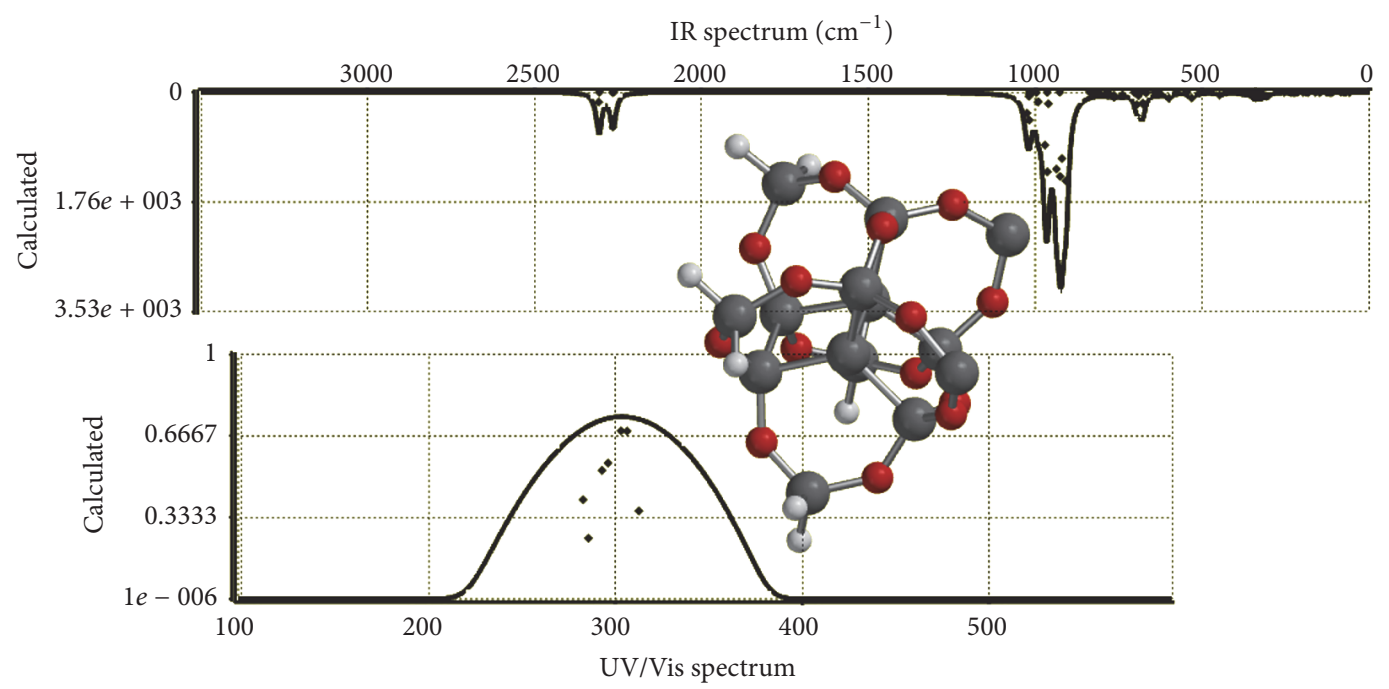

Figure 5: Case $\mathrm{Si}_{14} \mathrm{O}_{14}: \mathrm{H}_{8}$. 


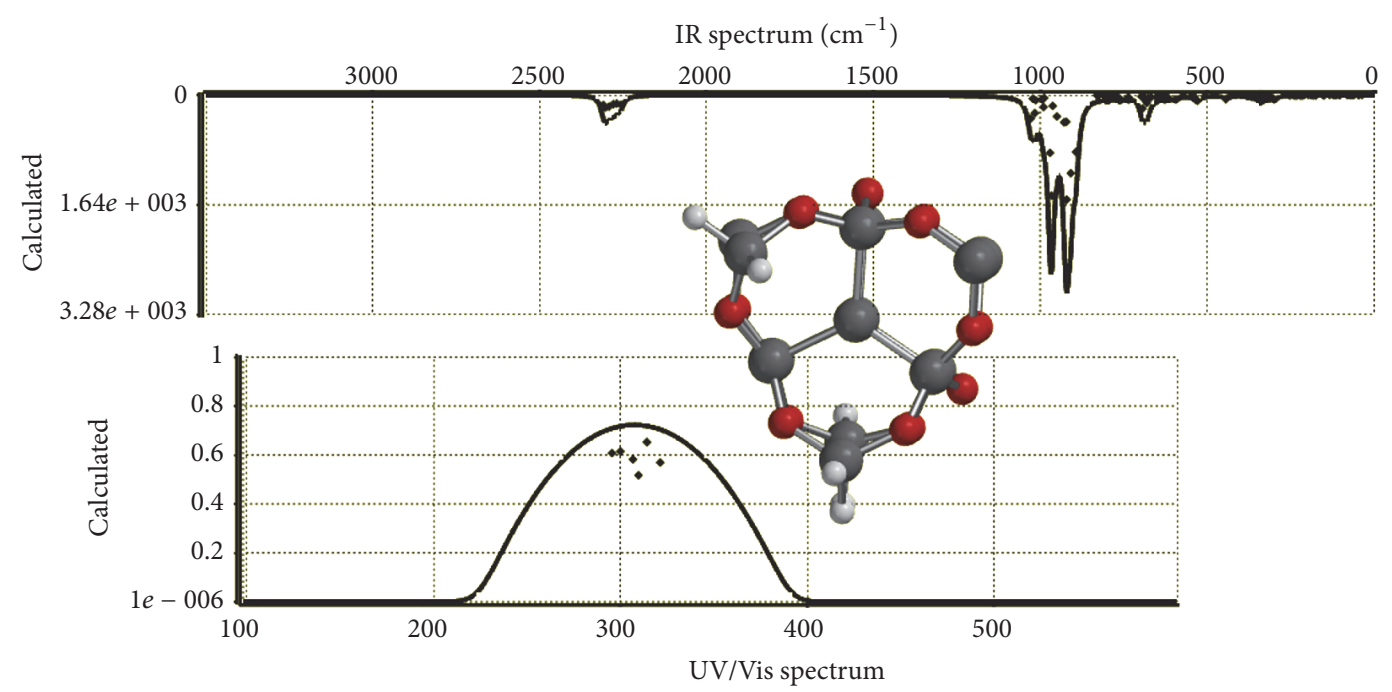

Figure 6: Case $\mathrm{Si}_{14} \mathrm{O}_{14}: \mathrm{H}_{6}$.

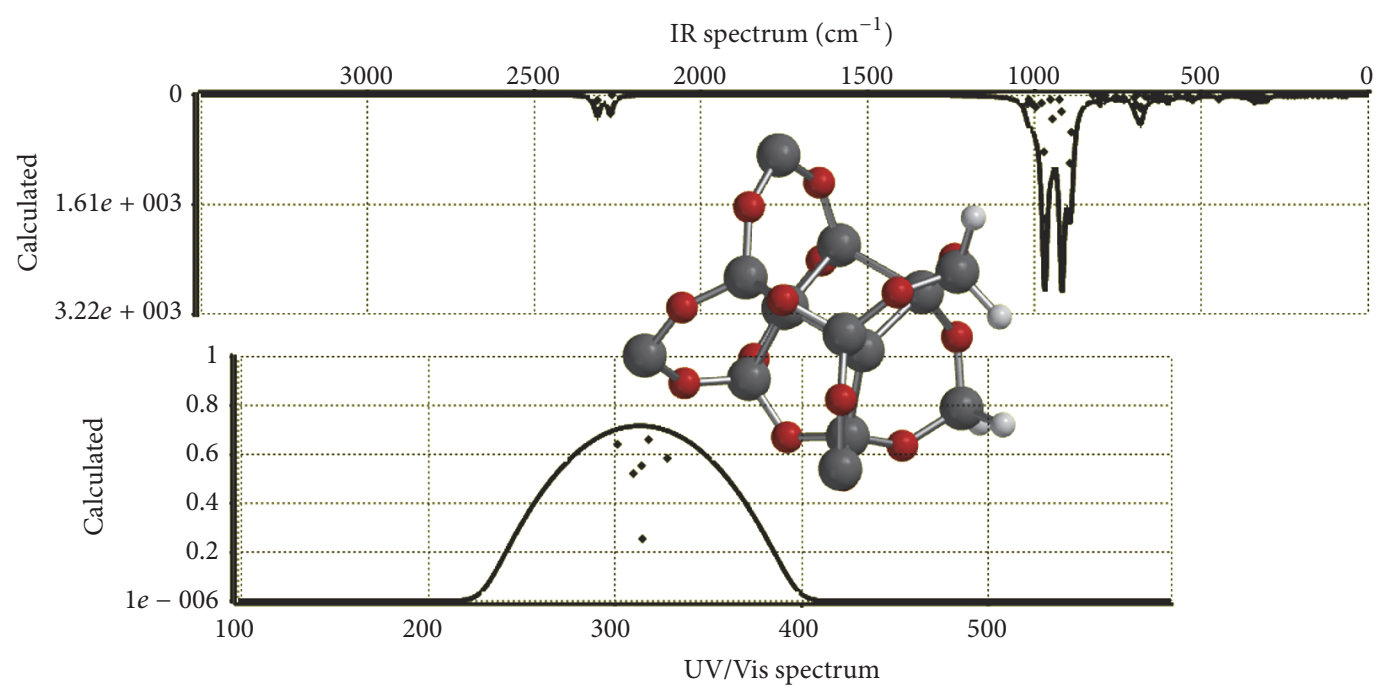

Figure 7: Case $\mathrm{Si}_{14} \mathrm{O}_{14}: \mathrm{H}_{4}$.

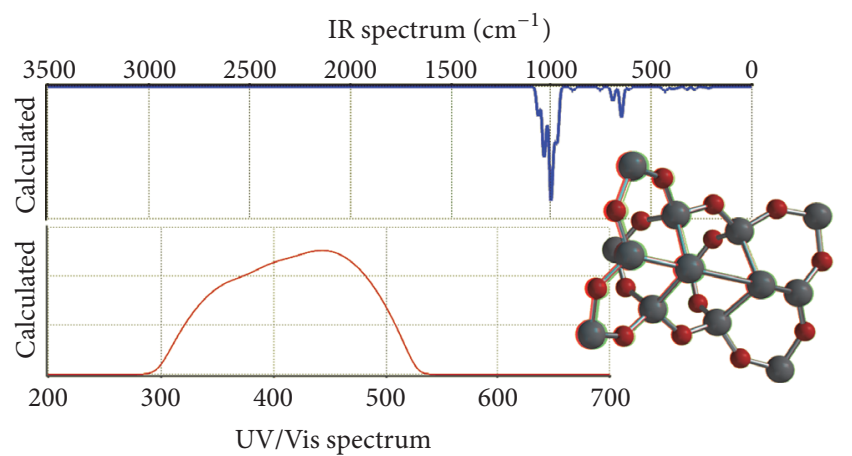

Figure 8: Case $\mathrm{Si}_{14} \mathrm{O}_{14}$.

in Figure 9 ranges from 500 to $2000 \mathrm{~cm}^{-1}$ and the plot is extended up to $2125 \mathrm{~cm}^{-1}$, but there is not any data beyond, which means that no experimental data were reported in the cited reference for the $\mathrm{Si}-\mathrm{H}$ bond. The spectrum of the thermal $\mathrm{SiO}_{2}$ structure is also shown as a reference in curve 1 . These spectra show the absorption peaks associated with stretching $\left(1084 \mathrm{~cm}^{-1}\right)$, bending $\left(812 \mathrm{~cm}^{-1}\right)$, and rocking $\left(458 \mathrm{~cm}^{-1}\right)$ vibration modes of the $\mathrm{Si}-\mathrm{O}-\mathrm{Si}$ bonds in $\mathrm{SiO}_{2}$ $[10,12,13]$. The position of the stretching absorption peak changes with the Ro value and with thermal treatments. In Figure 9, the abbreviation TT is employed to describe thermal treatment and AG refers to as-grown.

Despite the structural shape of the molecular structures shown in Figures 3-8, the structures are not quite different between them, except for the number of hydrogen atoms introduced. Intentionally the structures were rotated to give to the reader the best perspective of the atomic arrangement.

In this report, we have theoretically predicted a shift of the $\mathrm{Si}-\mathrm{O}$ stretching on phase vibration peak toward higher 
TABLE 2: Calculated optical properties for structures type $\mathrm{Si}_{14} \mathrm{O}_{14}: \mathrm{H}_{n}$.

\begin{tabular}{lcccc}
\hline Reference & Structure & $\begin{array}{c}\text { Wavelength with the } \\
\text { highest intensity emission } \\
(\mathrm{nm}) \text { in UV-Vis spectrum }\end{array}$ & $\begin{array}{c}\text { Frequency peak with the } \\
\text { highest intensity } \mathrm{cm}^{-1} \text { (due to } \\
\text { Si-O bonds) in FTIR spectrum }\end{array}$ & $\begin{array}{c}\text { Frequency due to Si-H bonds } \mathrm{cm}^{-1} \\
\text { (only peaks with the highest intensities } \\
\text { in FTIR spectrum are shown) }\end{array}$ \\
\hline Figure 3 & $\mathrm{Si}_{14} \mathrm{O}_{14}: \mathrm{H}_{12}$ & 268.7 & 934 & 2306 \\
Figure 4 & $\mathrm{Si}_{14} \mathrm{O}_{14}: \mathrm{H}_{10}$ & 292.5 & 925 & 2300 \\
Figure 5 & $\mathrm{Si}_{14} \mathrm{O}_{14}: \mathrm{H}_{8}$ & $303-306.2$ & 926 & 2264 and 2306 \\
Figure 6 & $\mathrm{Si}_{14} \mathrm{O}_{14}: \mathrm{H}_{6}$ & 314.1 & 922 & 2302 \\
Figure 7 & $\mathrm{Si}_{14} \mathrm{O}_{14}: \mathrm{H}_{4}$ & 317.9 & 925 & 2271 and 2309 \\
Figure 8 & $\mathrm{Si}_{14} \mathrm{O}_{14}$ & 444.4 & 996 & It does not exist \\
\hline
\end{tabular}

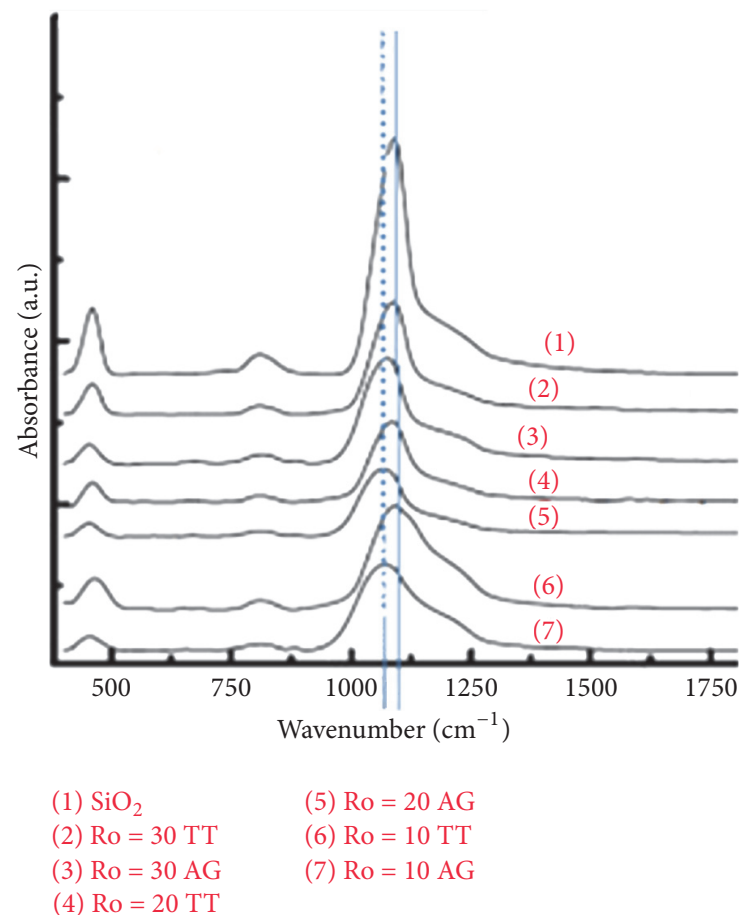

FIGURE 9: Experimental results for SRO films. The mismatched values for the experimental and theoretical peak positions are mainly attributed to the fact that reported experimental data are a mixture of silicon oxides, known as SRO, and in this work we only evaluated a single type of silicon oxide, namely, the $\left(\mathrm{Si}_{n} \mathrm{O}_{n}\right)$ structure. Adapted from Luna-López et al. [3].

energies accordingly as the number of hydrogen atoms is reduced (Table 2). This shift is experimentally confirmed by the experimental spectra reported in Figure 9, since the thermal annealing treatment of the SRO films produces a shift of the peak corresponding to the $\mathrm{Si}-\mathrm{O}$ stretching on phase vibration toward higher energies, regardless of the Ro value employed.

The Si-O stretching on phase vibration was predicted to be positioned in the range from 934 to $996 \mathrm{~cm}^{-1}$, as the number of $\mathrm{H}$ atoms reduces from 12 to zero in $\mathrm{Si}_{14} \mathrm{O}_{14}: \mathrm{H}_{x}$ structures. However, Luna-López et al. [3] find this peak shifted to $1061-1088 \mathrm{~cm}^{-1}$ in the experimental spectra of SRO films deposited with different values of $\mathrm{Ro}=10,20$, and 30 (Table 1 of [3]).

\section{Conclusions}

In this work, we have applied the model known as the Global Reaction Model in order to predict the theoretical luminescent behavior of the as-grown and annealed nanostructured Silicon Rich Oxide films where we have focused on the presence of hydrogen atoms as the key factor. We evaluate the PL spectrum of the as-grown SRO samples and also after the annealing procedure in which such samples are submitted and we have given evidence of the luminescent emission in the visible region of electromagnetic spectra, when the samples are fully dehydrogenated. Also, we calculated the theoretical FTIR spectra for as-grown and for partially and fully annealed structures. We have made comparisons of the results, obtained in this research, with those obtained experimentally, which have been reported in literature and we have found evidence of a good agreement between them. After making a comparison of the experimental and calculated band gaps, PL, and FTIR spectra, it conducts us to conclude that agglomerates type Si-O with a number of silicon atoms of eleven and fourteen would be present in SRO films deposited for $10<\mathrm{Ro}<20$. Finally, we can conclude that SRO films as-deposited frequently are not fully saturated.

\section{Disclosure}

The current affiliation for N. D. Espinosa-Torres, Postdoctoral Fellow, is Instituto de Energías Renovables, UNAM Campus Temixco, Privada Xochicalco s/n, 62580 Temixco, MOR, Mexico.

\section{Competing Interests}

The authors declare that there is no conflict of interests regarding the publication of this manuscript.

\section{Acknowledgments}

This work was supported by project VIEP-HEDJ-EXC16-I and Cuerpo Académico "Semiconductores Nanoestructurados y Orgánicos,” BUAP-CA-275. 


\section{References}

[1] P. Mutti, G. Ghislotti, S. Bertoni et al., "Room-temperature visible luminescence from silicon nanocrystals in silicon implanted $\mathrm{SiO}_{2}$ layers," Applied Physics Letters, vol. 6, no. 7, pp. 851-853, 1995.

[2] N. D. Espinosa-Torres, Theoretical study of the luminescent phenomena in silicon rich oxide [Ph.D. thesis], Centro de Investigación en Dispositivos Semiconductores, BUAP, 2015.

[3] J. A. Luna-López, J. Carrillo-López, M. Aceves-Mijares, A. Morales-Sánchez, and C. Falcony, "FTIR and photoluminescence of annealed silicon rich oxide films," Superficies y Vacío, vol. 22, no. 1, pp. 11-14, 2009, marzo de 2009 @Sociedad Mexicana de Ciencia y Tecnología de Superficies y Materiales.

[4] N. D. E. Torres, J. F. J. F. Gracia, and J. A. L. López, "Ab initio molecular orbital calculation for optical and electronic properties evaluation of small and medium size silicon nanoclusters found in silicon rich oxide films," Journal of Modern Physics, vol. 4, pp. 1-26, 2013.

[5] J. A. Luna-López, M. Aceves-Mijares, J. Carrillo-López, A. Morales-Sánchez, F. Flores-Gracia, and D. E. Vázquez Valerdi, "UV-Vis photodetector with silicon nanoparticles," in Photodetectors, S. Gateva, Ed., InTech, 2012.

[6] Spartan Tutorial, User's Guide Hehre, J. Warren, and W. S. Ohlinger, Spartan'14 Tutorial and User's Guide, Wavefunction, Inc., Irvine, Calif, USA, 2013.

[7] T. Morioka, S. Kimura, N. Tsuda, C. Kaito, Y. Saito, and C. Koike, "Study of the structure of silica film by infrared spectroscopy and electron diffraction analyses," Monthly Notices of the Royal Astronomical Society, vol. 299, pp. 78-82, 1998.

[8] T. Inokuma, Y. Kurata, and S. Hasewaga, "Cathodoluminescence properties of silicon nanocrystallites embedded in silicon oxide thin films," Journal of Luminescence, vol. 80, no. 1-4, pp. 247-251, 1998.

[9] R. López-Estopier, M. Aceves-Mijares, and C. Falcony, "Cathodo- and photo- luminescence of silicon rich oxide films obtained by LPCVD," in Cathodoluminescence, N. Yamamoto, Ed., InTech, 2012, http://www.itspozarica.edu.mx/carreras/ documentos/electronica/InTech-Cathodo.pdf.

[10] M. Aceves, D. Berman, J. Carranza, L. Berriel, and C. Domínguez, "UV DETECTORS: silicon-rich silicon oxide films boost UV sensitivity," Laser Focus World, vol. 41, no. 9, pp. 103105, 2005.

[11] M. Aceves-Mijares, N. D. Espinosa-Torres, F. Flores-Gracia et al., "Composition and emission characterization and computational simulation of silicon rich oxide films obtained by LPCVD," Surface and Interface Analysis, vol. 46, no. 4, pp. 216223, 2014.

[12] F. Ay and A. Aydinly, "Comparative investigation of hydrogen bonding in silicon based PECVD grown dielectrics for optical waveguides," Optical Materials, vol. 26, no. 1, pp. 33-46, 2004.

[13] P. G. Pai, S. S. Chao, Y. Takagi, and G. Lucovsky, "Infrared spectroscopic study of siox films produced by plasma enhanced chemical vapor-deposition," Journal of Vacuum Science \& Technology A: Vacuum, Surfaces, and Films, vol. 4, no. 3, pp. 689-694, 1986. 

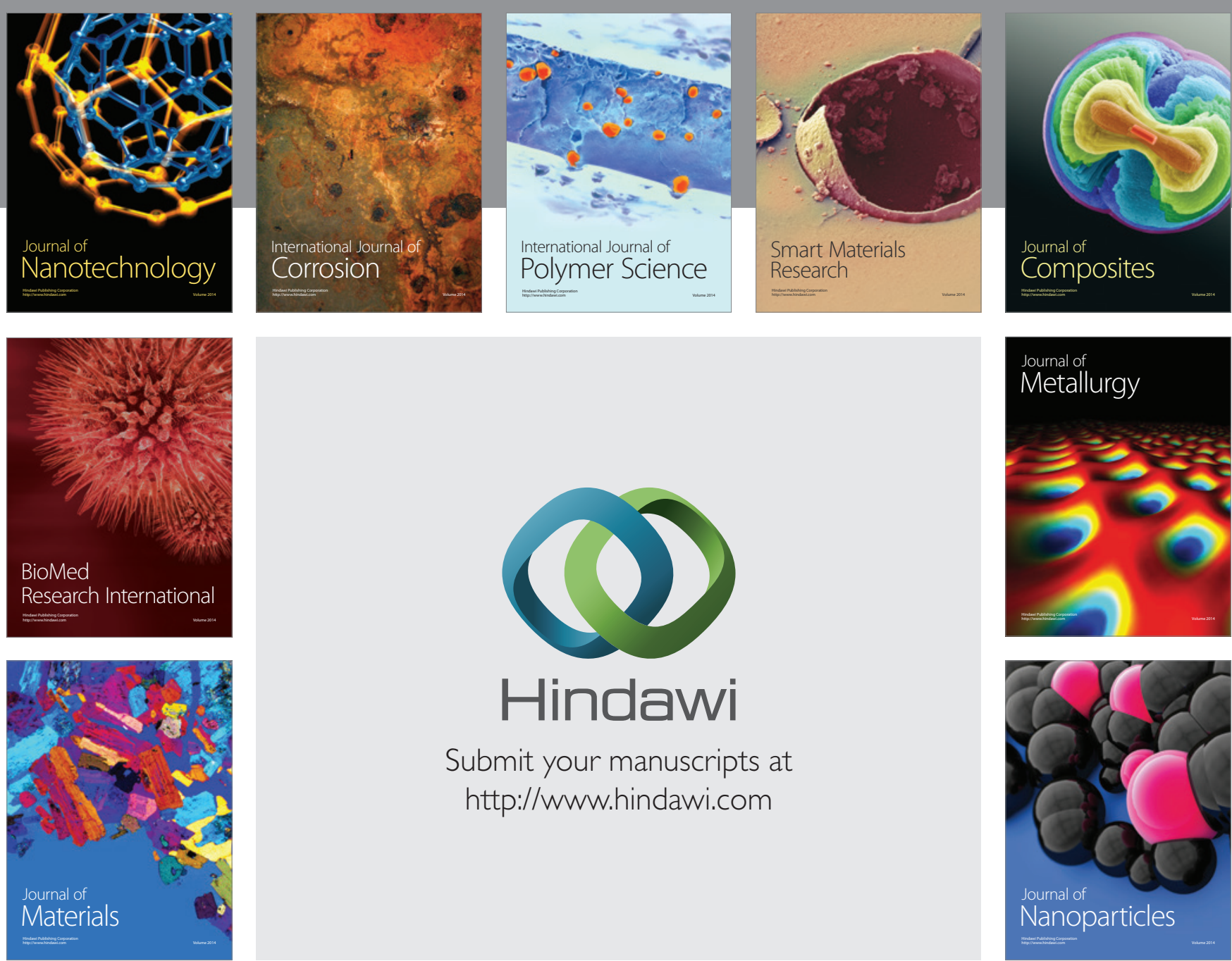

\section{Hindawi}

Submit your manuscripts at

http://www.hindawi.com

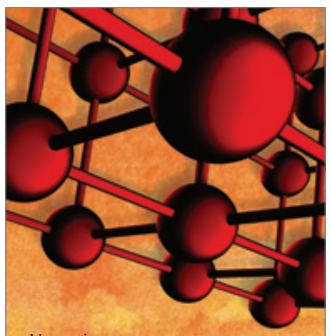

Materials Science and Engineering
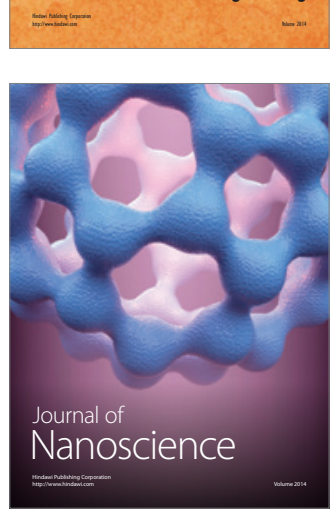
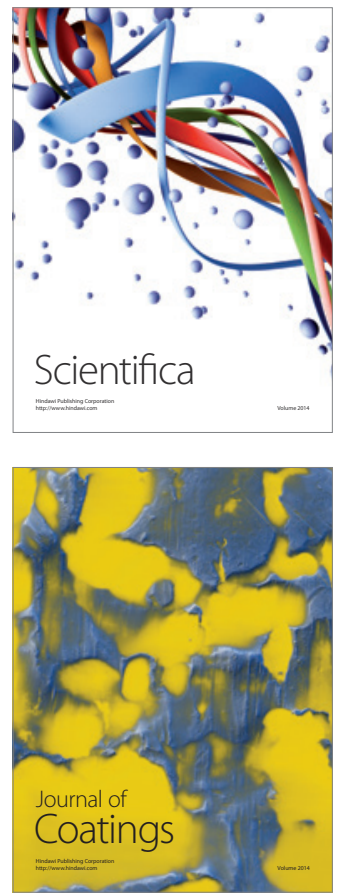
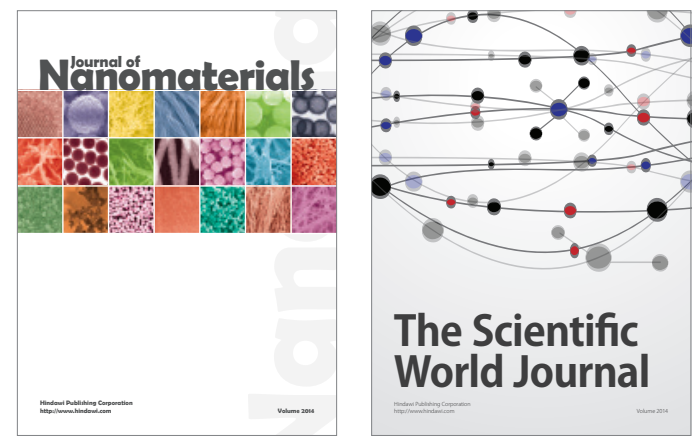

The Scientific World Journal
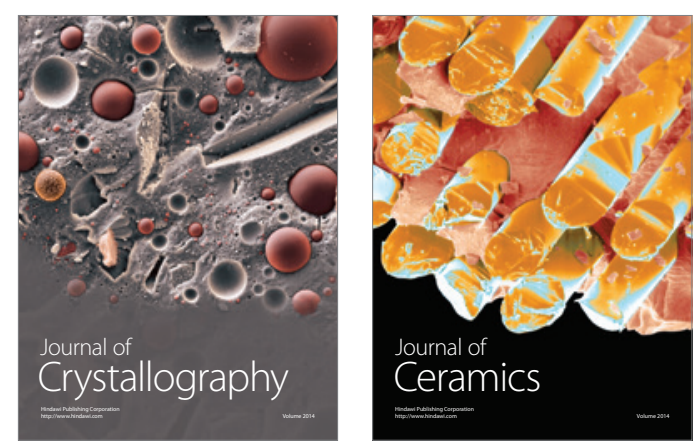
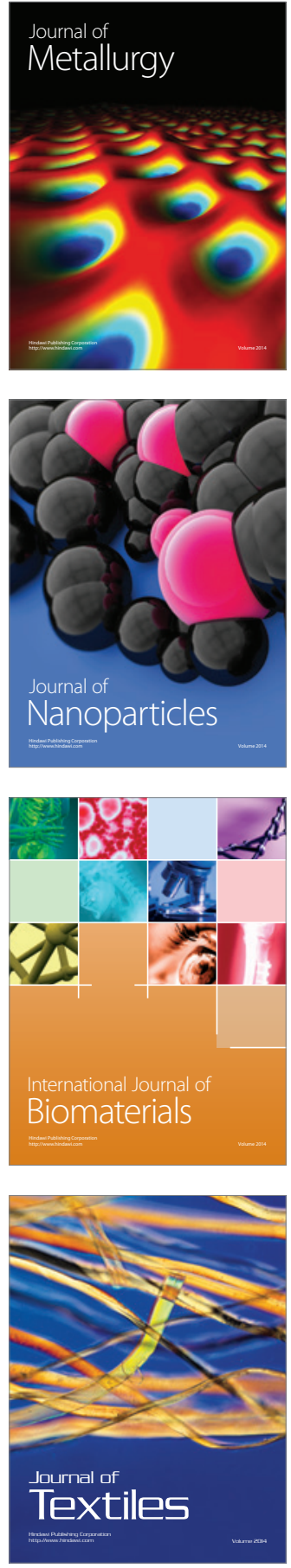